\title{
La representación del Estado en el discurso de la Asociación Madres de la Plaza de Mayo en Argentina
}

\author{
Alberto Javier Mayorga Rojel ${ }^{*}$ \\ Carlos del Valle Rojas**
}

\begin{abstract}
Resumen: En el presente trabajo se presentan algunos resultados obtenidos del estudio acerca de la configuración del Estado en el discurso político de las Madres de la Plaza de Mayo durante el 2001 - 2002. Para cumplir con lo enunciado, se realiza un análisis crítico del discurso con el objeto de identificar cómo el dispositivo utilizado por este movimiento social durante el periodo mencionado ocupa un conjunto de elementos discursivos que delimitan y/o fortalecen el sentido de la noción de Estado en Argentina y, a su vez, conforman las relaciones de significación que este tiene para el desarrollo democrático de un país.

Palabras clave: movimiento social, discurso político, Estado, representación , análisis del discurso.
\end{abstract}

\section{The argentine State representation in the discourse of social movement Madres de la Plaza de Mayo}

\begin{abstract}
The article presents some conclusions of the investigation about the representation of the Argentine State in the political discourse of social movement "Madres de la Plaza de Mayo" during 2001-2002. For such effect, a critical analysis of the discourse in order to identify how the discursive elements developed by this social movement during the foresaid period utilizes a set of discursive elements that limit or strengthen the meaning of the notion of State in Argentina, as well as it states the meaningful relations that this has for the democratic development of a country. This on the bases of the theoretical perspective worked by Joseph Courtés, Louis Panier and Jonathan Potter.
\end{abstract} analysis.

Key words: political discourse, social movement, Argentine State, discourse

\section{A representação do Estado no discurso das Mães da Praça de Mayo, na Argentina}

Resumo: Este artigo apresenta alguns resultados obtidos com o estudo sobre a configuração do Estado no discurso político das Mães da Plaza de Mayo durante os anos 2001-2002. Para cumprir com o enunciado, realiza uma analise critica de discurso com o objetivo de identificar como o dispositivo utilizado por

\footnotetext{
*Universidad de La Frontera, Temuco, Chile. Email: amayorga@ufro.cl

** Universidad de La Frontera, Temuco, Chile. Email: delvalle@ufro.cl
} 
este movimento social durante o período mencionado utiliza um conjunto de elementos discursivos que delimitam e/ou fortalecem o sentido da noção de Estado na Argentina e, por sua vez, conformam as relações de significação que este tem para o desenvolvimento democrático de um país.

Palavras-chave: movimentos sociais, discurso político, Estado, Representação, análise do discurso.

Recibido 13.04.2009

Aceptado: 13.01.2010

\section{Introducción}

Partiremos de la premisa que los movimientos sociales en América Latina se gestaron en el contexto de grandes desigualdades económicas y conflictos sociopolíticos que polarizaron durante los setenta y los ochenta a varias naciones del continente. En el marco de las disputas políticas de las décadas mencionadas, el objetivo de las diversas acciones de resistencia popular y de desobediencia civil eran las fuerzas militares y el Estado.

Además, durante este periodo ${ }^{1}$ es importante recalcar que la situación de crisis social y económica estimulada por los niveles de desempleo y por la sostenida desigualdad en la distribución de las riquezas como consecuencia de la acumulación de capital (financiada principalmente con el ahorro interno) y de la transformación de la estructura productiva (fortalecimiento de la ISI y disminución de la participación de la agricultura en el PIB), no se correspondía, por una parte, con una tasa de crecimiento promedio del 5,5 por ciento anual del producto interno bruto (PIB) y, por otra, con el 2,8 por ciento del producto per cápita regional (Halperín Donghi, T, Glade, W, Thorp, R, et al, 2002).

Dadas esas circunstancias, los beneficios económicos obtenidos por la mayoría de los países latinoamericanos durante tres décadas no tuvieron un impacto positivo en las condiciones de vida de la mayoría de la población, sino todo lo contrario, desde la perspectiva de los autores citados se evidenció -a partir de la crisis de los años ochenta- un recorte sustancial del gasto público (baja calidad de los servicios de salud y educación), caída de los salarios, aumento del desempleo y crecimiento del número de personas que vivían en condiciones precarias, es decir por debajo del nivel de pobreza.

\footnotetext{
1 “La región afrontó una profunda crisis durante los años ochenta, la que surgió de la gran deuda acumulada durante los años setenta y de los efectos recesivos del peor contexto externo desde los años treinta, tanto en el mercado de bienes como en el financiero. Durante esta década, la región afrontó el impacto combinado del incremento masivo de la subida real en la tasa LIBOR, un cese total de préstamos voluntarios en los mercados financieros internacionales, el estancamiento de la demanda de productos básicos por las economías de mercado desarrolladas (EMD) y una caída del 23 por ciento de los términos de intercambio entre 1980 y 1990” (Halperín Donghi, T, Glade, W, Thorp, R, et al, 2002: 346).
} 
Así entonces, podemos comprender las transformaciones políticas, económicas y sociales que han acaecido en Latinoamérica, donde la aplicación de reformas estructurales asociadas a la implementación del modelo neoliberal han conducido a los países ${ }^{2}$ en vías de desarrollo a disponer de un funcionamiento determinado por una lógica de antropofagia económico ${ }^{3}$ como única medida útil para fomentar un crecimiento sostenido en el tiempo, aumentar la inversión extranjera, reestructurar los modos de producción y consumo, controlar los índices inflacionarios y, por supuesto, cumplir con el pago de la deuda externa.

Por consiguiente, durante el periodo de aplicación del programa neoliberal ${ }^{4}$ en América Latina:

"La tensión entre capitalismo y democracia desapareció, porque la democracia [y el Estado] empezó a ser un régimen que en vez de producir redistribución social la destruye (...) Una democracia sin redistribución social no tiene problema con el capitalismo; al contrario, es el otro lado del capitalismo, es la forma más legítima de un Estado débil” (Boaventura de Sousa, 2006: 75, citado en Borón, 2006b: 290).

\section{Bajo estas condiciones económicas ${ }^{5} \mathrm{y}$ de ajustes estructurales, los}

2 En el marco de la crisis económica (década del 80), O`Donnell (1993: 85-86) plantea que
países como Chile, Bolivia y Argentina, compartieron los siguientes rasgos en común: 1) un
Estado que como principio del orden tiene una autoridad minúscula sobre la conducta de
muchos actores (...); 2) un movimiento obrero completamente derrotado en el sentido de
que ya no es capaz de oponerse a las políticas neoliberales, excepto con protestas desagregadas
y efímeras; 3) una clase capitalista que sustancialmente se devoró así misma, con los gana-
dores metamorfoseándose en conglomerados centrados financieramente y orientados hacia
fuera (...); y 4) un sentimiento generalizado de que la vida bajo una inflación continua e incier-
ta es tan insoportable que cualquier solución es preferible, incluso si esa solución ratifica un
mundo aún más desigual en el que se han perdido muchas formas de sociabilidad solidaria.
${ }^{3}$ La capacidad del hombre para devorar al hombre mediante la maquinaria económica.
${ }^{4}$ Según Quijano (1993: 214 ), mediante las siguientes proposiciones se puede comprender
como este poder mundial tiene la capacidad de cubrir (controlar) a la totalidad de la pobla-
ción: "Uno, es el primero donde en cada uno de los ámbitos de la existencia social están
articuladas todas las formas históricamente conocidas de control de las relaciones sociales
correspondientes, configurando en cada área una sola estructura con relaciones sistemáti-
cas entre sus componentes y del mismo modo en su conjunto. Dos, es el primero donde cada
una de esas estructuras de cada ámbito de existencia social, está bajo la hegemonía de una
institución producida dentro del proceso de formación y desarrollo de este mismo patrón de
poder. Así, en el control del trabajo, de sus recursos y de sus productos, está la empresa
capitalista; en el control del sexo, de sus recursos y productos, la familia burguesa; en el
control de la autoridad, sus recursos y productos, el Estado-nación; en el control de la
intersubjetividad, el eurocentrismo. Tres, cada una de esas instituciones existe en relacio-
nes de interdependencia con cada una de las otras. Por lo cual el patrón de poder está
configurado como un sistema”. ${ }^{5} \mathrm{Al}$ respecto, Eckstein (2001: 363-364) señala que "el neoliberalismo, basado en la premisa de la prioridad de la actividad del mercado sin trabas, fue asociado con la privatización 
movimientos sociales ${ }^{6}$ comienzan a desplegarse en el espacio público alimentados por las diversas situaciones intolerables y enajenantes vividas por los miembros de la sociedad civil ${ }^{7}$ ligados a los grupos sociales de mayor vulnerabilidad. Estas condiciones, sin embargo, son articuladas mediante las dinámicas dictatoriales de los diversos gobiernos militares de la época, la reiterativa violación de los Derechos Humanos (DD.HH), las carencias económicas y la inestabilidad política evidenciada en el marco de un Estado ${ }^{8}$ caracterizado por su accionar represor y utilizado por los grupos de poder para potenciar el proyecto de reorganización de la sociedad.

En este sentido, podemos afirmar que las dictaduras en América Latina, instancia donde la implementación de las reformas neoliberales han

de la actividad económica, la eliminación de los subsidios y los controles de precios del estado, la liberalización de los precios y la reducción tanto de las barreras al comercio como de las restricciones a la inversión extranjera. [Por lo tanto], el discurso oficial ensalza las virtudes del orden, la economía del mercado sin obstáculos, los derechos políticos y la modernidad".

${ }^{6}$ Podemos afirmar -apoyados en los planteamientos de Manuel Antonio Garretón (2000), Alain Touraine (1995, 2000) y Claus Offe (1992)- que el movimiento social obrero sustentaba su lucha sobre la base de la relación conflictiva entre el capital (modos de producción) y el proletariado (trabajo), lo que, a su vez, articulaba el sentido de este tipo de movimiento social como un actor político central en el marco de la sociedad industrial. Entonces, este movimiento obrero situado en el contexto latinoamericano de la denominada - en palabras de Garretón - matriz nacional popular tuvo una importancia en la región hasta 1970 producto de la transformación política y económica que afectó a la relación gestada entre el Estado y la sociedad durante la primera mitad del S.XX. Sin embargo, los nuevos movimientos sociales defensores de los DD.HH, de los grupos étnicos, de la juventud, de la educación, de las mujeres, entre otros, utilizaron la experiencia del movimiento obrero para articular una determinada identidad, formas de lucha y organización.

${ }^{7}$ Según Manuel Antonio Garretón (2006: 57), se puede "entender la sociedad civil como aquel conjunto de actores que contribuye específicamente a la reconstrucción de la polis y la ciudadanía, como aquel sujeto de demandas y proyectos que reconstituye efectivamente el espacio donde la sociedad y el país se producen como tales".

${ }^{8}$ En el presente trabajo entendemos al Estado como el "conjunto de instituciones y de relaciones sociales que normalmente penetra y controla el territorio y los habitantes que ese conjunto pretende delimitar geográficamente [...] Además, el Estado se entiende como un sistema legal, es decir un entramado de reglas legalmente sancionadas que penetran y codeterminan numerosos relaciones sociales” (O`Donnell, 2004: 149-150). Sin embargo, cabe recordar que la figura del Estado no puede estar -únicamente- asociado al concepto de lo público (institucional), la burocracia (procedimientos) y el aparato estatal (infraestructura y sistema organizacional), sino que -a su vez- en palabras de Guillermo O`Donnell (1993: 64): "El Estado es también, y no menos primariamente, un conjunto de relaciones sociales que establece cierto orden en un territorio determinado y, finalmente, lo respalda con una capacidad coercitiva centralizada”. En síntesis, debemos destacar que la noción de Estado presentada se complementa con un enfoque teórico-crítico acerca de las disfuncionalidades impuestas por el neoliberalismo en el plano del crecimiento económico en América Latina y que nos obliga ha reflexionar acerca del significado adscrito a la figura del Estado en el marco de las nuevas lógicas económicas, políticas y sociales que se construyen en América Latina. 
configurado la doble dimensión del Estado 9 , permitieron el surgimiento de movimientos sociales unificados bajo la bandera de lucha contra el imperialismo pero, específicamente, contra el capitalismo, la represión popular y el autoritarismo del Estado.

Dentro de los movimientos sociales vinculados al aspecto de los DD.HH surgidos en este contexto se encuentran la Asociación Madres de la Plaza de Mayo. Esta agrupación nace el 30 de abril de 1977, cerca de un año después (24 de marzo de 1976) del golpe militar en Argentina, como respuesta a las continuas detenciones, abusos, torturas y asesinatos de personas contrarias al régimen por parte de los agentes represores de la dictadura $^{10}$.

Tal como es expresado por Galante, Luque y Fuks (2006: 260):

"Eligieron también reclamar por sus hijos desde su rol de madres (alejando a los "padres", a otros familiares varones y a jóvenes en general de un exposición considerada más vulnerable que la propia) intentando apelar a unos de los valores -la familia- que la dictadura decía defender, así como al imaginario sacralizado en la cultura argentina sobre la madre y la maternidad".

Si bien la iniciativa de las Madres de la Plaza de Mayo estaba centrada en la necesidad de empoderarse como colectivo para solicitar al Estado, por una parte, el retorno de los hijos desparecidos durante la dictadura en Argentina y, por otra, el reconocimiento de los Derechos Humanos, con

\footnotetext{
${ }^{9}$ Desde nuestra perspectiva el Estado se ve afectado por lo siguiente: 1) Se debilita su capacidad para redistribuir equitativamente las riquezas, cohesionar a la ciudadanía a partir de un proyecto común y gestionar la eficiente participación democrática (no meramente instrumental) de la sociedad civil. 2) Se fortalece su papel de interlocutor (no interventor) entre el capital internacional y el mercado local, regulador de la relación entre el mercado y la sociedad civil, dinamizador de las relaciones internacionales como mecanismo de compenetración económica-política entre los países industrializados y las naciones en vías de desarrollo, y, finalmente, facilitador de las modificaciones necesarias (desregulaciones) para la subsistencia de determinados sistemas productivos y/o cambios de éstos. Por su parte, Garretón (2000: 116) plantea que: "El Estado combina, por un lado, dimensiones simbólicas, institucionales, instrumentales, y actorales o de agente relativamente autónomo. Por otro lado, ejerce funciones coercitivas, reguladores, redistributivas, integrativas, dependiendo de qué esfera de la sociedad se trata”. En el fondo, para el mencionado autor el Estado es el conjunto de instituciones y organizaciones que tienen el carácter público y que en un espacio territorial determinado poseen el monopolio legítimo de la fuerza. En este sentido, el Estado cristaliza las diversas relaciones de poder y dominación que se observan en la sociedad y, además, posee la capacidad de ser un agente de la unidad nacional y el promotor del modelo de desarrollo que impulsa a la nación.

${ }^{10}$ Véase Investigación sobre la "Historia de las Madres de la Plaza de Mayo”, coordinada por Miguel Galante. Proyecto "Organizaciones y Movimientos Sociales ante el Terrorismo de Estado (1776-1983)”. Programa de Historia Oral (Etnohistoria) de la Facultad de Filosofía y Letras de la Universidad de Buenos Aires.
} 
el tiempo fueron fortaleciendo la legitimidad de sus demandas ${ }^{11}$ dentro de la desfragmentada sociedad civil trasandina y lograron articular dos acciones de resistencia visibles para la sociedad, los medios de comunicación y el gobierno:

1. Producción e instalación de un discurso contrahegemónico sustentado en los principios de libertad y democracia.

2. Resemantización del espacio público "plaza” como lugar de encuentro y reconocimiento con la comunidad nacional e internacional.

\section{En tal sentido,}

“...ellas apelaron no sólo a ese difundido imaginario en torno a la maternidad, sino también a uno más histórico y político: la Plaza de Mayo como escena pública que entonces sería suya. "Señoras y señores, tenemos que juntarnos en la Plaza de Mayo, como hicieron nuestros mayores, a reclamar por nuestros hijos”, habría pregonado Azucena Villaflor De Vicenti1 ${ }^{12}$ ” (Ibid: 261).

Así entonces, las Madres de la Plaza de Mayo logran unificar un discurso de resistencia que interpela tanto a la sociedad civil como al gobierno militar, lo que desencadena una producción discursiva desde sus inicios hasta nuestros días. Por lo tanto, si atendemos al estudio realizado por Martín D’Alessandro ${ }^{13}$ acerca de este Movimiento de Derechos Humanos, podemos identificar tres momentos discursivos importantes que fueron analizados: Dictadura, Democracia (pre - juicio) y Democracia (post juicio). Este último periodo corresponde a los años 1986 - 1992.

\footnotetext{
${ }^{11}$ Según García y Palermo (en Camacho y Menjívar, 2005: 412): "Esta demanda se reformula al cabo del tiempo y accede sin perder su carácter ético al plano político: comienza a ir más allá de la acción puramente reactiva o defensiva, como se ha calificado a este tipo de participación, para expresar en términos de valores constituyentes del bien común e interpretar al Estado; "para que esto no se repita”, “para que todos tengan libertad”. Esta reformulación influye decisivamente en la identidad del Movimiento de los Derechos Humanos que dejará de ser la expresión de respuesta directa y sectorial a la brutal represión que afecta a individuos íntimamente vinculados, para ingresar de lleno en el campo de lo colectivo, al espacio de lo social y lo político, desde donde se apelará a todos y cada uno de los ciudadanos, cuyos derechos están siendo igualmente afectados aunque en apariencia queden fuera del problema".

${ }^{12}$ En los testimonios obtenidos por el Programa de Historia Oral (Etnohistoria) de la Facultad de Filosofía y Letras de la Universidad de Buenos Aires, en el marco de la investigación sobre la "Historia de las Madres de la Plaza de Mayo", coordinada por Miguel Galante, se identifica a Azucena Villaflor De Vicenti (secuestrada en diciembre de 1977) como una de las fundadoras de esta agrupación de DD.HH.

${ }^{13}$ Véase D’Alessandro, M. (1998), "Los movimientos sociales en la transición democrática. El caso de las Madres de la Plaza de Mayo: Sentimiento y discurso”, en Revista América Latina Hoy, $N^{\circ}$ 20, pp.41-45.
} 
De modo que en este trabajo nos centraremos en determinar la representación del Estado en el discurso de las Madres de la Plaza de Mayo durante el periodo de la crisis de 2001 - 2002. Para cumplir con el objetivo enunciado, se procederá a la selección de un corpus acotado que será definido en virtud de criterios de selección descritos en el apartado metodológico del presente documento y que será suficiente para observar como el dispositivo $^{14}$ utilizado por este movimiento social durante el periodo mencionado configura un conjunto de elementos discursivos que delimitan y/o fortalecen el sentido de Estado en Argentina y, a su vez, conforman las relaciones de significación instauradas para el desarrollo democrático de un Estado-nación.

Ahora bien, creemos necesario precisar, por un lado, que la agrupación de DD.HH Madres de la Plaza de Mayo ${ }^{15}$ es entendida y categorizada como un movimiento social en la medida que cumple con las siguientes características establecidas por Federico Rossi (2006: 273):

1) Su concepción como redes informarles de interacción compuestas por individuos, grupos y/u organizaciones,

2) la presencia de solidaridades y creencias compartidas que constituyan una sensación de pertenencia y provean de una identidad colectiva,

3) la presencia de antagonismos sobre el control de algún recurso (material o simbólico), es decir, la existencia de acción colectiva orientada al conflicto,

\footnotetext{
${ }^{14}$ Para Michel Foucault (1978, citado en Jäger, 2001: 71) el concepto de dispositivo se debe entender como "un conjunto decisivamente heterogéneo que abarca los discursos, instituciones, instituciones arquitectónicas, decisiones regladas, leyes, medidas administrativas, afirmaciones científicas, enseñanzas filosóficas, morales o filantrópicas, en resumen, lo que se dice y lo que no se dice”. Se erige por ende, una comprensión del discurso (dispositivo) como práctica social y objeto material que, por una parte, porta en sus entrañas un conocimiento y, por otra, determina una configuración de la realidad, lo que -en palabras de Siegfried Jager (Ibid: 69)- "permite a los discursos ejercer un poder porque transportan un saber con el que se nutre la conciencia colectiva e individual, así como el fundamento de la acción formativa que moldea la realidad”.

${ }^{15}$ En el caso de la agrupación Madres de la Plaza de Mayo, es necesario subrayar que su conformación como tal se gesta sobre la base de un contexto político de dictadura y centra su atención en la acción colectiva con el objeto de producir algún cambio significativo en las decisiones de los gobernantes o, en su caso, un cambio (derrocamiento) de gobierno (militar). Por tal razón, se puede asumir que las Madres de la Plaza de Mayo formarían parte de los nuevos movimientos sociales y, por ende, se alejarían del sentido y objetivos propuestos por el movimiento social obrero. Al respecto, Claus Offe establece (citado en Rossi, 2006: 270): “...el nuevo paradigma nacido con posterioridad a la sociedad industrial implicaba que los nuevos movimientos sociales se presentasen -a diferencia del movimiento obrero- como reacciones meta-políticas que cuestionan el orden social en la búsqueda de una democracia radical no basada en la representación clásica”.
} 
4) el uso de la protesta (aunque no le es exclusivo), y

5) su perduración en el tiempo más allá de las protestas.

Y por otro, que -a pesar de la falta de militancia política de muchas de las mujeres que dieron vida a esta agrupación- la participación de algunas de las Madres en diversos colectivos sociales u organizaciones sindicales permitió compartir algunas experiencias que sirvieron de base para su conformación y posterior organización ${ }^{16}$. 272-273):

Vale la pena advertir, en palabras de Galante, Luque y Fuks (2006:

"Sin dudas, Madres con experiencia sindical (algunos testimonios indican a Azucena en el gremio telefónico, otros en la empresa Siam), o en luchas políticas del exilio paraguayo (Esther Careaga en el movimiento febrerista) ante la dictadura de Stroessner o en el movimiento católico tercermundista (Mari Ponce activista en la Iglesia Santa Cruz de los Misioneros Pasionistas), jugaron un rol importante en las primeras actividades que dieron identidad a las Madres y en sus primeras formas de organización.

Una vez precisado lo anterior, debemos aclarar que nuestra intención no es desarrollar un balance histórico de los movimientos sociales y, mucho menos, describir a cabalidad algún tipo de movimiento social particular como es el caso de la Asociación Madres de la Plaza de Mayo ${ }^{17}$, sino más bien nuestras pretensiones se focalizan en la realización de un análisis crítico del discurso político producido por este movimiento social de DD.HH

\footnotetext{
${ }^{16}$ Para Igor Goicovic (1996: 11) "las formas de articulación del movimiento social, sus experiencias de lucha y las relaciones que construye en la cotidianeidad deben apuntar a perfilar y consensuar dicho programa [rearticulación del proyecto histórico-popular]; mientras que las formas de ocupación del espacio público y el carácter (solidario) de las relaciones que construyen sociedad deben convertirse en sus ejes estratégicos”.

${ }^{17} \mathrm{Si}$ bien no es un objetivo del presente trabajo establecer una descripción histórica de la Asociación de las Madres de la Plaza de Mayo, creemos necesario mencionar que este movimiento durante el año 1986 sufre una división dentro de sus miembros producto de una posición radical que se niega a la exhumación de cuerpos para el reconocimiento e identificación. Esta posición radical fue liderada por la actual presidenta del movimiento social, Hebe de Bonafini. Por su parte, las integrantes de la posición contraria a la dispuesta por Bonafini, se separan de la agrupación original y forman la Asociación Madres de la Plaza de Mayo-Línea Fundadora. No obstante, en este ensayo se ha definido analizar los discursos producidos por la Asociación de las Madres de la Plaza de Mayo en virtud de su antigüedad como movimiento (grupo nacido el jueves 30 de abril de 1977 y que se mantuvo después de la división) y, a su vez, por el tipo de interacción permanente que establecen con el Estado. En el marco de lo anterior, se pueden establecer tres momentos claves: 1) Durante la dictadura y los primeros años de la democracia. 2) Durante el gobierno de Menen (considerando como punto de inflexión el indulto a los militares entre los años 1989 y 1990). 3) Desde la crisis económica de 2001 en argentina hasta la actualidad.
} 
durante un periodo de tiempo determinado por un acontecimiento económico y político que se transforma en un punto de inflexión relevante en la medida que denota una crisis en la sociedad argentina.

\section{Movimientos sociales en América Latina. Referencias conceptuales}

A los fines de este trabajo, procederemos a plantear algunas definiciones necesarias para lograr una mejor comprensión de la noción de movimiento social. Concepto que no ha estado alejado de múltiples definiciones propuestas por investigadores sociales adscritos a enfoques norteamericanos, europeos y latinoamericanos. Al respecto resulta oportuno destacar algunos autores que han desarrollado propuestas acerca de los movimientos sociales en Estados Unidos, Europa y América Latina: Smelser (1989), Blumer (1946), Meyer y Staggenborg (1996), Tarrow (1998, 1997), McAdam (1982), Ch. Tilly (2004, 2005), Melucci (1996), Touraine (1995, 2000), Garretón (2002), Camacho y Menjívar (2005), Eckstein (2001), Boaventura de Sousa (2004), Borón (2006a), Calderón, Fernando y Elizabeth Jelin (1987), Svampa (2005) y Auyero (2004), entre otros.

Ahora bien, quisiéramos partir por precisar que los movimientos sociales se gestaron ${ }^{18}$ en sociedades donde se visualizó un desarrollo importante del ordenamiento geopolítico a partir del establecimiento y funcionamiento del Estado-nación, del ordenamiento económico-social mediante el desarrollo del capitalismo, el establecimiento de un interés y participación en la dinámica política moderna por parte de los ciudadanos y una mayor presencia de individuos viviendo en centros urbanos. Por lo tanto, esta interacción entre Estado y ciudadano(a) -en palabras de Sidney Tarrow (1998: 200)- logra articular la configuración de un movimiento social $^{19}$ enmarcado por el contexto de la modernidad.

"The social movement was not an automatic outcome of modernization but emerged from the long, tormented, but ultimately interactive process of state formation and citizenship and from the diffusion of these forms of interaction over time and across territory".

\footnotetext{
${ }^{18}$ Para Charles Tilly (citado en Rossi, 2006) el primer movimiento social corresponde al movimiento abolicionista (Society for the Abolition of the Slave Trade).

${ }^{19}$ Asimismo, Sidney Tarrow (1998: 6) establece que la identidad, solidaridad e intereses comunes son elementos relevantes en la conformación y sinergia de los movimientos sociales: "The most common demoninator of social movement is thus interest, but interest is no more than an objective category imposed by the observer. It is participants' recognition of their common interests than translates the potential for a movement into action. By mobilizing consensus, movement entrepreneurs play an important role in stimulating such consensus. But leaders can only create a social movement when they tap more deep-rooted feeling of solidarity or identity".
} 
Así entonces, podemos apreciar que la modernidad, el desarrollo del capitalismo, la participación política y la lucha por aspectos tanto económicos como simbólicos por parte de los ciudadanos(as) y, no menos importante, la existencia de un espacio público donde las diversas fuerzas sociales convergen, han sido los elementos catalizadores para la conformación de los movimientos sociales como actores políticos ${ }^{20}$ capaces de cuestionar el orden y, en consecuencia, dinamizar los diversos conflictos sociales presentes en espacios territoriales determinados y -en la actualidad- a nivel transnacional ${ }^{21}$.

Por tal razón, lo propuesto por Meyer y Staggenborg (1996: 16301631), reafirman lo antes señalado:

"The social movement as we know it came into being with the growth of modern nation-states and developed into a familiar means of pressing claims. [Therefore], advocates of particular causes employ social movement forms when they believe, first, that such forms are necesary to persue their goals and, second, that they are potentially efficacious"

En este mismo sentido, es importante destacar la breve propuesta de Sidney Tarrow (1998: 4) acerca de la noción de movimiento social:

"[A social movement consists of] collective challenges based on common purposes and social solidarities, in sustained interaction with elites, opponents, and authorities".

Es por ello que, desde la perspectiva de Alain Touraine (1995: 88-89):

"Sólo hay movimiento social si la acción colectiva se atribuye objetivos societarios, es decir reconoce valores o interés general de la sociedad y, por consiguiente, no reduce la vida política al enfrentamiento de campos o de clases, al mismo tiempo que organiza y desarrolla los conflictos (...). Es por eso que puede [el movimiento social] servir de principio de reconstrucción meditada, discutida y decidida de una sociedad fundada sobre principios de justicia, liber-

\footnotetext{
${ }^{20}$ Vale la pena enriquecer esta breve reflexión acerca de los movimientos sociales con algunos planteamientos teóricos propuestos por Charles Tilly (2005: 20), quien señala que la diferencia y distanciamiento que existe entre los movimientos sociales y los partidos políticos u otras formas de hacer política en nuestras sociedades contemporáneas, se sustenta en la combinación específica de llevar a cabo 1) campañas sostenidas en defensa de demandas colectivas, 2) actuaciones múltiples, incluyendo asambleas públicas, manifestaciones, comunicados de prensa y la creación de asociaciones, redes y coaliciones con fines específicos, y 3) muestras coordinadas de WURC -Worthiness (Valía), Unity (Unidad), Numbers (Número), Commitment (Compromiso)- en defensa de los activistas, partidarios y/o objetos de sus peticiones. [Las cursivas fueron incluidas para remarcar la traducción de cada concepto].

${ }^{21}$ En el caso de este último aspecto, véase Sidney Tarrow (2005).
} 
tad y respeto por el ser humano, que son exactamente aquellos sobre los cuales descansa la democracia”.

En otras palabras, todo movimiento social contiene:

"Un conjunto de sectores sociales, hegemonizado y/o dominado por una clase social y reproduce las contradicciones propias del momento histórico, es decir, el movimiento social se encuentra inmerso y es parte de las pugnas sociales que se expresan en la formación social. [En consecuencia], el movimiento social no es la expresión exclusiva de una clase social, más bien, es la expresión de varios proyectos de clase que pugnan por la hegemonía y/o dominación del potencial social contenido en el movimiento" (Gandásegui, citado en Camacho y Menjívar, 2005: 126).

Por consiguiente, según Meyer y Staggenborg (1996: 1634),

"Social movement can influence policy, alter political alignments, and raise the public profile and salience of particular issues. Movement can also create collective action frames, demonstrate the efficacy of various means of political action, and draw media attention that activates balancing norms in mainstream media. Finally, social movement can create or magnify critical events to which their opponents can respond."

Por tal razón, los movimientos sociales deben considerar mantener activas sus dinámicas de resistencia centradas en la permanente custodia de los grupos de poder y, por ende, evaluar en el marco de sus acciones colectivas la proyección histórica dentro de una dimensión social donde se expresan las relaciones políticas, económicas y sociales propias de las estrategias de consenso y coerción ejercidas por el Estado como por los organismos económicos supranacionales.

Es decir, la dinámica del diálogo asimétrico que existe entre Estado y movimiento social, implica que estos últimos sean concientes de la desigualdad que se evidencia en el orden establecido por el primero.

"El Estado alega en diversas formas -desde los discursos explícitos hasta la recurrente invocación del simbolismo de la independencia de la nación- que es el creador del orden que discutimos anteriormente. Nosotros vemos que ese orden es desigual en todas las sociedades, aun cuando desde el ápice del Estado se sostenga que resulta igual para todos los miembros de la nación” (O`Donnell, 1993: 66).

En este breve marco analítico acerca de la noción de movimiento social, es necesario acentuar que la característica de autonomía, es decir la capacidad que posee todo movimiento social para contemplar un grado mínimo de autonomía en relación con el establecimiento de vínculos con el Estado y los agentes económicos dominantes, se transforma en el pilar 
central de la resistencia y las reivindicaciones producto de la interacción política moderna entre quienes ostentan el poder y los colectivos sociales. Considerando lo dicho, se sostiene la posibilidad de asumir que los movimientos sociales representarían, en palabras de Noé (citado en Camacho y Menjívar, 2005: 387): "una alternativa de búsqueda de soluciones para los problemas que se encuentran en la base del desarrollo social de la sociedad capitalista”.

Sin embargo, desde nuestra perspectiva:

"En la actualidad no podemos obviar que las crisis económicas, las políticas represivas ${ }^{22}$ y el establecimientos de una lógica neoliberal han provocado -específicamente en América Latina- una desfragmentación de la sociedad, debilitaron el papel del Estado en relación al campo de intervención económica, gatillaron una reducción del gasto público (educación, salud y protección social) y acrecentaron los niveles de desigualdad en la distribución de las riquezas e inequidad en el acceso de bienes públicos de calidad" (Mayorga, Del Valle y Nitrihual, 2009: 169-170).

\section{Y agregamos:}

“Así entonces, no sería una exageración pensar que la dinámica económica adoptada por los estados latinoamericanos, por una parte, tiende a reforzar los espacios colonizados por los grupos económicos tanto nacionales como transnacionales, favorece la rebelión de las élites ${ }^{23} \mathrm{y}$ desmantela las formas de poder público; $y$, por otra, ha naturalizado la reducción de los niveles de participación ciudadana, promueve la eliminación de toda resistencia político-social (sindicatos), transforma el espacio público y provoca una deslegitimación (desconfianza) de las instituciones políticas (Estado y partidos políticos) incapaces de dar una respuesta a las demandas sociales de la clase media y de los grupos de mayor riesgo y vulnerabilidad" (Ibid: 170).

\footnotetext{
${ }^{22}$ Según Guillermo O`Donnell (1993: 84): “Un país que experimentó hace poco esos problemas, pero que parece haber encontrado una salida, es Chile. Con una eficiencia que habría admirado Lenín, las políticas del régimen de Pinochet lograron la destrucción de casi todo lo que quedaba (después del gobierno de Allende) de una burguesía orientada al mercado interno, a la sustitución de las importaciones -y que estaba demasiado agradecida por haber sido salvada como clase como para ponerse a organizar ninguna oposición concertada-. Desde luego, el gobierno de Pinochet también reprimió brutalmente los sindicatos obreros y los partidos políticos que podrían haber articulado una oposición eficaz a sus políticas”. ${ }^{23}$ La rebelión de las élites es una idea acuñada por Christopher Lasch (1995, citado en Iazzetta, 2007: 92) para explicar el comportamiento (solidaridad intragrupal) de los grupos sociales favorecidos y que da forma a un nuevo tipo de exclusión social voluntaria explicitada en la acción centrípeta de los grupos dominantes (destinar el financiamiento y apoyo para el desarrollo de servicios y bienes consumibles sólo por un grupo específico de individuos, por ejemplo espacios de entretención como clubes de golf ).
} 
Frente a propuestas categóricas de esta índole, nos parece de vital importancia manifestar que los nuevos movimientos sociales ${ }^{24}$ se ven obligados a compartir las múltiples experiencias de los colectivos para fortalecer su capacidad de interacción global, intervención en la esfera pública, presencia en los medios de comunicación y participación directa en el desarrollo local. Pero cabe aclarar, que dicha acción que podemos categorizar como contrahegemónica ${ }^{25}$, se enfrenta a una realidad latinoamericana marcada por la dinámica de un sistema económico excluyente, sustentada en regímenes democráticos disfrazados con vestiduras de diálogos y consensos, y, finalmente, adornada por el manto de las crisis económicas, de los partidos políticos y los respectivos sistemas de partidos.

A pesar del complejo escenario descrito, sostenemos que:

"La articulación de una contrahegemonía se entiende como otro desafío enmarcado dentro de las posibilidades presentes de los movimientos sociales. Así entonces, estas articulaciones (redes activas) que se producen mediante los procesos comunicativos entre los diversos movimientos sociales evita la dispersión de los mismos, potencia su reconocimiento como agentes sociales del cambio y la resistencia, pero no aglutina a los distintos movimientos bajo un mismo propósito (eje) temático transversal. No obstante, debemos considerar que las disfuncionalidades del Estado frente al mercado y los modos de producción del sujeto social determinados por el neoliberalismo, se transforman en los elementos principales que explican la tensión y las demandas realizadas por los colectivos en el contexto de la dinámica del mercado global” (Ibid: 171).

En definitiva, quisiéramos dejar enunciado -de manera tangencialque los diversos movimientos sociales presentes en la sociedad latinoamericana pueden ser incorporados a la matriz conceptual de multitud ${ }^{26}$, lo que

\footnotetext{
${ }^{24}$ Siguiendo las ideas planteadas por Susana Eckstein (2001), se puede establecer que los diversos movimientos sociales surgidos a partir de 1990 poseen las siguientes bases sociales de apoyo: 1. Bases en las relaciones económicas (movimiento campesino armados y no armados, movimientos sindicales, movimientos por la vivienda y movimientos de deudores); 2. Bases en el género; 3. Base racial, étnica e indígena; y 4. Base religiosa.

${ }^{25}$ Para Boaventura de Sousa Santos y Leonardo Avritzer (2004: 67) "la globalización contrahegemónica pasa, en este campo, por esas articulaciones [redes transnacionales y experiencias locales]. Esas articulaciones dan credibilidad y fortalecen las prácticas locales por el simple hecho que las transforman en eslabones de redes y movimientos más amplios y con mayor capacidad transformadora”.

${ }^{26}$ En palabras de Antonio Negri y Giuseppe Cocco (2006: 211-212) "la multitud aparece entonces como el nombre de un conjunto de singularidades sin trascendencia, es decir, un pueblo con respecto al cual la soberanía no puede ser separada de su ejercicio. Contrariamente a lo que afirmaban Hobbes, Rousseau y Hegel (y muchos observadores contemporáneos interesados en la crisis argentina), la multitud sin soberano es lo opuesto al caos, a la violencia y a la guerra civil. En la Argentina, donde comienza la multitud y su potencia se acaba el poder del Estado (¡del terror!) y del caos de los mercados: terminó el miedo”. Por
} 
conlleva una comprensión del conjunto de movimientos sociales como la suma de subjetividades y singularidades determinantes de una postura contraria a la desvinculación del concepto y el ejercicio, es decir determinantes de la soberanía de los movimientos sociales y de su efectiva acción en el plano de las relaciones sociales y las luchas por las demandas contra los excesos cometidos producto del poder autoritario que ejercen los grupos económicos y políticos (Ibid).

\section{Propuesta metodológica}

El presente trabajo se inscribe dentro de los estudios acerca de los movimientos sociales y el análisis crítico de sus prácticas discursivas. Así entonces, al centrar nuestro interés en determinar la representación del Estado en el discurso de las Madres de la Plaza de Mayo durante el periodo de la crisis de 2001-2002, estamos dejando establecido los límites significativos que tiene el estudio y se postula entender el concepto de representación discursiva como la capacidad de los dispositivos discursivos para configurar y/o reforzar actitudes, creencias e ideologías sobre la base de una producción de significados que poseen un sustento socio-cognitivo en el conjunto de creencias socialmente compartidas por el colectivo de un país y que en consecuencia, permite disponer de una coherencia textual entre proposiciones y discursos a través de los marcos referenciales comunes en complemento con la dimensión contextual que engloba a las prácticas discursivas cotidianas.

De este modo, el modelo de análisis del discurso que se utiliza para cumplir con el objetivo mencionado en el presente trabajo, está configurado sobre la base de las perspectivas teóricas trabajadas por J. Courtés (1995), J -C. Giroud y L. Panier (1988), en el marco del análisis semiótico textual, y por medio de las ideas de J. Potter (1998), quien propone identificar las representaciones discursivas a partir de las factualidades reconocibles en todo texto, las cuales han sido re-elaboradas desde la perspectiva teóricometodológica trabajada por Del Valle (2006: 169-179).

De esta forma, en la investigación se aplica un análisis del discurso

su parte, Daniel Bensaïd (2006: 45-46) destaca el notorio éxito que ha tenido la noción de multitud entre los movimientos de resistencia al capitalismo global y establece, por una parte, que "es comprensible que las abigarradas multitudes que se expresan en las movilizaciones argentinas, en las que se juntan asalariados, piqueteros, madres de la Plaza de Mayo, estudiantes golpeados por la crisis universitaria, capas medias arruinadas por la debacle del peso, etcétera, se puedan reconocer como pueblo o como multitud”, y, por otra, que dicho término Multitud "es teóricamente confusa, sociológicamente inconsistente, filosóficamente dudosa y estratégicamente hueca”. En consecuencia, nuestro planteamiento final de carácter tangencial queda sujeto a una revisión más acuciosa para evaluar su posible inconsistencia o indeterminación conceptual - tal como lo plantea Bensaïd en su texto "Clases, Plebes, Multitudes". [Las cursivas son nuestras]. 
que nos permite estudiar el discurso de las Madres de la Plaza de Mayo, con la intención de observar como el dispositivo utilizado por este movimiento social durante el periodo mencionado configura un conjunto de elementos discursivos que delimitan y/o fortalecen el sentido del Estado en Argentina y, a su vez, conforman las relaciones de significación que se disponen en virtud del desarrollo democrático de un Estado-nación.

Así entonces, el material que es analizado en este estudio lo constituye un corpus de 5 discursos políticos (epistolares) que fueron elaborados por la Asociación de las Madres de la Plaza de Mayo para su conocimiento público con el objetivo de evidenciar la posición de este movimiento social frente a la crisis económica y social que afectó(a) a la República Argentina.

\begin{tabular}{|c|c|c|}
\hline Identificación & Título del Discurso & $\begin{array}{l}\text { Fecha de } \\
\text { publicación }\end{array}$ \\
\hline $\begin{array}{l}\text { Discurso Politico } \\
\mathrm{N}^{\circ} 1\end{array}$ & $\begin{array}{c}\text { Carta de las Madres al Presidente Adolfo } \\
\text { Rodriguez Saá }\end{array}$ & $\begin{array}{l}24 \text { de diciembre de } \\
2001\end{array}$ \\
\hline $\begin{array}{l}\text { Discurso Politico } \\
\qquad \mathrm{N}^{\circ} 2\end{array}$ & $\begin{array}{l}\text { Carta entregada por las Madres al } \\
\text { Presidente de la Nación Eduardo Duhalde } \\
\text { el } 3 \text { de enero de } 2002\end{array}$ & 3 de enero de 2002 \\
\hline $\begin{array}{c}\text { Discurso Politico } \\
N^{\circ} 3\end{array}$ & El otro soy yo & $\begin{array}{l}24 \text { de marzo de } \\
2002\end{array}$ \\
\hline $\begin{array}{l}\text { Discurso Politico } \\
N^{0} 4\end{array}$ & $\begin{array}{c}\text { Carta abierta al Presidente Eduardo } \\
\text { Duhalde, a la dirigencia politica, a la } \\
\text { burocracia sindical. }\end{array}$ & $\begin{array}{l}28 \text { de marzo de } \\
2002\end{array}$ \\
\hline $\begin{array}{l}\text { Discurso Politico } \\
N^{\circ} 5\end{array}$ & $\begin{array}{l}\text { Carta abierta al Presidente Eduardo } \\
\text { Duhalde, los ministros, senadores y } \\
\text { diputados de la Nación. }\end{array}$ & 5 de junio de 2002 \\
\hline
\end{tabular}

En resumen, si las representaciones discursivas están sustentadas en un principio ideológico que logra unificar el sentido de un discurso, entonces se hace evidente la facultad que posee la configuración discursiva para categorizar, resemantizar, articular y disponer de la construcción social de sentido en torno a un colectivo, sujeto u objeto sobre la base de creencias compartidas socioculturalmente y, de esta manera, se establece un discurso verosímil capaz de reforzar en la memoria histórica las imágenes que se han transmitido por medio de las diversas operaciones socializadoras de cada comunidad.

Por consiguiente, aunque admitimos que la justificación del modelo de análisis será presentado de manera sucinta, reafirmamos la importancia que adquiere el análisis del discurso para lograr determinar y comprender, en el marco de la producción de sentido que el discurso como acción 
comunicativa simbólica genera de manera progresiva, la representación del Estado en el discurso de las Madres de la Plaza de Mayo durante el periodo de la crisis de $2001-2002$.

\section{Modelo de análisis del discurso}

El modelo de análisis del discurso utilizado en este estudio, procura descubrir, revelar e identificar conexiones que a menudo se encuentran implícitas en los discursos y, en consecuencia, el modelo trabaja sobre manifestaciones explícitas e implícitas existentes en los textos, como es el caso de los actores, roles, lugares simbólicos, valores temáticos, situaciones discursivas y recorridos figurativos de aquellos elementos discursivos que delimitan y/o fortalecen una representación del Estado en el discurso de la Asociación de las Madres de la Plaza de Mayo.

\begin{tabular}{|c|c|}
\hline \multicolumn{2}{|c|}{ DIMENSIÓN DISCURSIVA } \\
\hline FIGURAS & $\begin{array}{l}\text { Las figuras son elementos de significación más } \\
\text { o menos determinados, pero reconocibles en } \\
\text { la lectura. Se dividen en actores, tiempo y lu- } \\
\text { gares. }\end{array}$ \\
\hline $\begin{array}{l}\text { RECORRIDOS } \\
\text { FIGURATIVOS }\end{array}$ & $\begin{array}{l}\text { Las figuras están dispuestas en recorridos fi- } \\
\text { gurativos. Esto se debe entender como el modo } \\
\text { en que el texto utiliza las figuras y la manera } \\
\text { como se desarrolla una figura en el texto. }\end{array}$ \\
\hline VALORES TEMÁTICOS & $\begin{array}{l}\text { Es el sentido que se construye a partir de las } \\
\text { relaciones entre las figuras y sus recorridos fi- } \\
\text { gurativos. Por lo tanto, las figuras tienen un } \\
\text { valor a partir de su relación con otras figuras. } \\
\text { Es la especificidad de las figuras, es decir, el } \\
\text { papel que cumple cada una en el texto. }\end{array}$ \\
\hline $\begin{array}{l}\text { SITUACIONES } \\
\text { DISCUSIVAS }\end{array}$ & $\begin{array}{l}\text { Todo texto dispone a los actores en un(os) } \\
\text { tiempo(s) y en un (os) lugar(es), permitiendo } \\
\text { esta disposición la lectura de un texto a partir } \\
\text { de la identificación de situaciones discursivas } \\
\text { (relaciones entre figuras). }\end{array}$ \\
\hline \multicolumn{2}{|c|}{ DIMENSIÓN FACTUAL } \\
\hline DISCURSO EMPIRISTA & $\begin{array}{l}\text { “...no se limita a centrarse en los datos sino } \\
\text { que los construye como si tuvieran una agen- } \\
\text { cia propia” (Potter, 1998: 152). }\end{array}$ \\
\hline
\end{tabular}




\begin{tabular}{|c|c|c|c|c|}
\hline \multicolumn{2}{|c|}{$\begin{array}{l}\text { FABRICACIÓN DEL } \\
\text { CONSENSO }\end{array}$} & \multicolumn{3}{|c|}{$\begin{array}{l}\text { “...los participantes tienden a construir corro- } \\
\text { boración cuando elaboran y socavan relatos } \\
\text { [pues] los procedimientos para la construcción } \\
\text { de hechos no trabajan de manera aislada. Tie- } \\
\text { nen la misma probabilidad de que se recurra a } \\
\text { ellos conjuntamente” (Ibid: 152-153). }\end{array}$} \\
\hline \multicolumn{2}{|c|}{$\begin{array}{l}\text { DETALLES EN } \\
\text { LA NARRACIÓN }\end{array}$} & \multicolumn{3}{|c|}{$\begin{array}{l}\text { "los datos específicos de una descripción, son } \\
\text { cruciales para la actividad a la que se destina } \\
\text { la descripción [y] son descripciones detalla- } \\
\text { das con minuciosidad" (Ibid: 154). }\end{array}$} \\
\hline \multicolumn{2}{|c|}{$\begin{array}{l}\text { MAXIMIZACIÓN / } \\
\text { MINIMIZACIÓN }\end{array}$} & \multicolumn{3}{|c|}{$\begin{array}{l}\text { “la formulación de 'casos extremos’ [y] que } \\
\text { consiste en utilizar los extremos de las dimen- } \\
\text { siones descriptivas pertinentes” (Ibid: 238). }\end{array}$} \\
\hline \multicolumn{2}{|c|}{$\begin{array}{l}\text { NORMALIZACIÓN / } \\
\text { ANORMALIZACIÓN }\end{array}$} & \multicolumn{3}{|c|}{$\begin{array}{l}\text { “...describir una acción que, por consenso, se } \\
\text { considera anormal o extraña [utilizando] una } \\
\text { organización discursiva que describe una ac- } \\
\text { tividad y que, al mismo tiempo, proporciona } \\
\text { pistas para verla como anormal o extraña [por } \\
\text { lo cual] la cuestión de la anormalidad está es- } \\
\text { trechamente vinculada con la cuestión de la } \\
\text { regularidad” (Ibid: } 247-248 \text { ). }\end{array}$} \\
\hline \multicolumn{5}{|c|}{ DIMENSIÓN SEMIÓTICA (CUADRADO SEMIÓTICO) } \\
\hline \multicolumn{2}{|c|}{$\begin{array}{l}\text { RELACIONES DE } \\
\text { CONTRARIEDAD }\end{array}$} & \multicolumn{3}{|c|}{$\begin{array}{l}\text { Relación lógica entre A y B, y entre NO B y } \\
\text { NO A. }\end{array}$} \\
\hline \multicolumn{2}{|c|}{$\begin{array}{l}\text { RELACIONES DE } \\
\text { CONTRADICCIÓN }\end{array}$} & \multicolumn{3}{|c|}{$\begin{array}{l}\text { Relación lógica entre A y NO A, y entre B y } \\
\text { NO B. }\end{array}$} \\
\hline \multicolumn{2}{|c|}{$\begin{array}{l}\text { RELACIONES DE } \\
\text { COMPLEMENTARIEDAD }\end{array}$} & \multicolumn{3}{|c|}{ Relación lógica entre A y NO B, y B y NO A. } \\
\hline A & \multicolumn{2}{|c|}{ NO A } & $\mathrm{B}$ & NO B \\
\hline $\begin{array}{l}\text { Representación } \\
\text { lógica del SER. }\end{array}$ & \multicolumn{2}{|c|}{$\begin{array}{l}\text { Representación } \\
\text { lógica del } \\
\text { NO SER. }\end{array}$} & $\begin{array}{l}\text { Representación } \\
\text { lógica del } \\
\text { PARECER. }\end{array}$ & $\begin{array}{l}\text { Representación } \\
\text { lógica del } \\
\text { NO PARECER. }\end{array}$ \\
\hline
\end{tabular}

\section{Resultados parciales}

Antes de comenzar es necesario destacar que en el marco de la disposición de los resultados, no se presentarán la totalidad de las tablas generadas a partir del proceso de análisis, sino que procederemos a seleccionar y entregar los elementos más relevantes del proceso en virtud del desarro- 
llo del presente estudio y del objetivo planteado al comienzo de este trabajo. Por lo tanto, nuestra intención es configurar una entrega ordenada y lógica de los resultados parciales obtenidos mediante la aplicación del modelo de análisis considerando el actual trabajo de investigación que se desarrolla, determinando para ello una reconstrucción de valores temáticos y recorridos figurativos mediante las relaciones discursivas que se gestan a partir de las figuras dispuestas dentro de las dinámicas de los textos.

En este sentido, la configuración de redes lógico-semánticas y la descripción de factualidades se complementan para determinar el sentido del discurso y la significación que adquiere la noción de Estado dentro del discurso de las Madres de la Plaza de Mayo.

Así entonces, cabe destacar como punto inicial que en los discursos se puede observar la disposición de figuras antagonistas que establecen o determinan las relaciones de significación sobre la bases del juego de oposición corrupción - resistencia. De esta forma, los representantes del Estado (Presidente, Gobernadores, Diputados, Senadores, Concejales, Políticos y Jueces) son identificados como los responsables de las reiteradas injusticias, del hambre y la desolación del pueblo argentino. Por tal razón, la representación del Estado comienza a ser configurada desde la fabricación de un consenso acerca de los abusos, violencia, represión, castigo y crueldad que impera en la sociedad argentina.

Ante ello, la instalación de la figura Terrorismo de Estado durante la $21^{\text {a }}$ Marcha de Resistencia convocada por las Madres de la Plaza de Mayo, es utilizada bajo la modalidad intertextual que asienta un reconocimiento público dentro del discurso en torno a la responsabilidad del Estado en la crisis económica y en los abusos cometidos contra la Nación. Incluso, la significación que se adscribe al sacrificio y defensa del pueblo por parte de Hebe de Bonafini (Presidenta de la Asociación de las Madres de la Plaza de Mayo) se sustenta sobre la base de la acusación contra las autoridades miembros del sistema político por su participación y -reiteramos- responsabilidad en la situación de caos, muerte y hambre que soporta el pueblo argentino.

Frente a este panorama de desolación producido por la irresponsabilidad de las autoridades políticas, las Madres de la Plaza de Mayo demandan la liberación inmediata de los dirigentes sociales y políticos que han sido detenidos, procesados y encarcelados injustamente por acciones de resistencia contra el poder económico y político corrupto que inunda las bases democráticas del pueblo. Para el cumplimiento de esta acción, el conjunto de los discursos analizados están dirigidos al Presidente de la Nación. Figura política que es interpelada por la Asociación de las Madres de la Plaza de Mayo para el cumplimiento de las demandas exigidas por el pueblo argentino y que, además, forman parte del compromiso establecido por el Presidente Eduardo Duhalde.

De la misma forma, en los discursos se recurre en reiteradas ocasiones a la narración de detalles de los acontecimientos y hechos puntuales 
que gestan un simbolismo de reconocimiento y solidaridad con el pueblo argentino que se representa en las figuras de los Piqueteros, Hijos, Niños, Asambleas Barriales, Revolucionarios Latinoamericanos, Pueblo, Nación y Luchadores Populares. Todo ellos configuran una oposición antagónica y significativa frente al sentido que se dispone en torno al Estado, puesto que el sentido que se construye a partir de las relaciones entre las figuras logra representarlos como el rostro del sufrimiento, dolor y desesperación causado por la acción de los gobiernos corruptos, de un Estado represor y por la crisis económica. A su vez, son el referente directo de la defensa del pueblo y sus acciones son justificadas en virtud de un terrorismo de Estado que golpea permanentemente al pueblo argentino y latinoamericano.

Por su parte, al describir a los EE.UU, el FMI y los sistemas financieros internacionales como agentes promotores del terrorismo de Estado, Hebe de Bonafini estructura un discurso sustentado sobre la base de un vínculo político entre las figuras recién nombradas y la figura del sistema político argentino, con el objeto de denotar la capacidad del Estado trasandino para transformarse en un servidor-esclavo de las potencias mundiales en virtud del apoyo y respaldo a la medidas económicas que se aplican antes, durante y posterior a la crisis de 2001. Por lo demás, la figura de EE.UU es identificado en el discurso de las Madres de la Plaza de Mayo con el imperialismo, el uso de la fuerza militar, el disciplinamiento del pueblo, la acción de presión económica y el control de las acciones de la élite política argentina.

Así entonces, el Estado que, por consenso, se considera anormal en su actuar es utilizando por algunos políticos ladrones como una fuente de riqueza para los grupos de poder y como un gatillador de la miseria y violencia que afecta a los miembros más vulnerables de la sociedad civil argentina.

En el fondo, las figuras, los recorridos figurativos, los valores temáticos, la fabricación de consenso, la maximización de algunos eventos y las relaciones de significación de mayor relevancia que se identificaron en el discurso de las Madres de la Plaza de Mayo, son marcadores jerárquicos que permiten una representación del Estado centrada en los valores de corrupción, injusticia, inestabilidad, crisis, conflicto, decadencia, servidumbre y responsabilidad.

En definitiva, los discursos públicos (mediáticos, políticos, epistolares, entre otros) poseen cierta dependencia de factores externos como referencias históricas, políticas, económicas y sociales de orden coyuntural, lo que se traduce en la acción que denominaremos complementariedad discursiva-contextual. O sea, es factible observar en toda producción discursiva una intertextualidad (conjunto de relaciones) que permite al individuo interpretar el sentido (o los sentidos) de un discurso mediante una comprensión de sí mismo y de los otros (discursos). De tal manera, lo anterior se complementa con lo enunciado por Costa y Mozejko (2001: 87): 
"El enunciador propone su modo de representación de los hechos haciendo uso de estrategias que tienden a convertirlo en aceptable por un enunciatario con competencias que le permitirían rechazar el modelo propuesto. [En consecuencia] el sujeto primero no está en condiciones de imponer su versión sin tener el cuidado de legitimarse como productor de sentido, verosimilizar su discurso apoyándose en las convenciones y provocar en el enunciatario pasiones que lo impulsen a adoptar como propio lo que el enunciador le dice que debe”.

A continuación, se presenta un cuadro con una breve descripción de los elementos significativos que sustentan la configuración de las prácticas discursivas de las Madres de la Plaza de Mayo durante los años 2001-2002.

\begin{tabular}{|c|c|c|}
\hline FIGURA & RECORRIDO FIGURATIVO & VALOR TEMÁTICO \\
\hline $\begin{array}{l}\text { Hebe de } \\
\text { Bonafini }\end{array}$ & $\begin{array}{l}\text { Presidenta de la Asociación } \\
\text { de Madres de la Plaza de } \\
\text { Mayo. Figura actor que repre- } \\
\text { senta al movimiento social y } \\
\text { que se dirige al representan- } \\
\text { te máximo del Estado -Pre- } \\
\text { sidente de la Nación- para } \\
\text { exigir una serie de medidas } \\
\text { que permitirán crear un país } \\
\text { más justo y democrático. A su } \\
\text { vez, acusa a las autoridades } \\
\text { miembros del sistema políti- } \\
\text { co del caos, la muerte y el } \\
\text { hambre que soporta el pueblo } \\
\text { argentino. }\end{array}$ & $\begin{array}{l}\text { Demanda } \\
\text { Presión política } \\
\text { Liderazgo } \\
\text { Representación } \\
\text { popular } \\
\text { Dolor } \\
\text { Molestia } \\
\text { Compromiso } \\
\text { Defensa } \\
\text { Sacrificio }\end{array}$ \\
\hline $\begin{array}{l}\text { Comisión } \\
\text { Directiva de las } \\
\text { Madres de la } \\
\text { Plaza de Mayo }\end{array}$ & $\begin{array}{l}\text { Conjunto de personas que son } \\
\text { miembros de la Asociación de } \\
\text { la Madres de la Plaza de } \\
\text { Mayo y que fueron elegidas } \\
\text { como parte de la directiva de } \\
\text { la asociación. Este grupo en } \\
\text { representación de los intere- } \\
\text { ses del colectivo solicita a su } \\
\text { Presidenta establecer contac- } \\
\text { to con el Presidente de la } \\
\text { Nación para exigir una serie } \\
\text { de medidas que permitirán } \\
\text { crear un país más justo y de- } \\
\text { mocrático. }\end{array}$ & $\begin{array}{l}\text { Consenso } \\
\text { Representación del } \\
\text { colectivo } \\
\text { Respaldo } \\
\text { Cohesión } \\
\text { Defensa }\end{array}$ \\
\hline
\end{tabular}




\begin{tabular}{|c|c|c|}
\hline $\begin{array}{l}\text { Adolfo } \\
\text { Rodríguez Saá } \\
\text { (Discurso N 1) } \\
\text { Eduardo } \\
\text { Duhalde } \\
\text { (Discurso } \mathrm{N}^{\circ} 2 \text { ) }\end{array}$ & $\begin{array}{l}\text { Presidente de la Nación. Figu- } \\
\text { ra Actor que es interpelado por } \\
\text { la Asociación de las Madres de } \\
\text { la Plaza de Mayo para el cum- } \\
\text { plimiento de las demandas exi- } \\
\text { gidas por el Pueblo Argentino. }\end{array}$ & $\begin{array}{l}\text { Autoridad } \\
\text { Representante de la } \\
\text { Nación } \\
\text { Conflicto } \\
\text { Compromiso } \\
\text { Reconocimiento } \\
\text { Corrupción }\end{array}$ \\
\hline $\begin{array}{l}\text { Presos Políticos } \\
\text { Dirigentes } \\
\text { Sociales }\end{array}$ & $\begin{array}{l}\text { Identificación de los miembros } \\
\text { de la sociedad civil que han } \\
\text { sido detenidos, encarcelados y } \\
\text { procesados por acciones de re- } \\
\text { sistencia contra el poder eco- } \\
\text { nómico y político corrupto. }\end{array}$ & $\begin{array}{l}\text { Reconocimiento } \\
\text { Dolor } \\
\text { Injusticia } \\
\text { Necesidad } \\
\text { Resistencia } \\
\text { Sacrificio }\end{array}$ \\
\hline $\begin{array}{l}\text { Fuerzas de } \\
\text { Seguridad }\end{array}$ & $\begin{array}{l}\text { Representantes del poder coer- } \\
\text { citivo y represor del Estado. } \\
\text { Figura actor que es identifica- } \\
\text { do como el responsable del } \\
\text { dolor y la represión contra el } \\
\text { indefenso pueblo argentino. }\end{array}$ & $\begin{array}{l}\text { Violencia } \\
\text { Represión } \\
\text { Inmunidad } \\
\text { Representación del } \\
\text { Estado } \\
\text { Corrupción }\end{array}$ \\
\hline $\begin{array}{l}\text { Personal del } \\
\text { Estado }\end{array}$ & $\begin{array}{l}\text { Figura actor utilizada para } \\
\text { identificar a los Diputados, } \\
\text { Senadores y Jueces de la Na- } \\
\text { ción. Conjunto de sujetos que } \\
\text { son responsables de la corrup- } \\
\text { ción y el usufructo desmedido } \\
\text { de los dineros del Estado. }\end{array}$ & $\begin{array}{l}\text { Corrupción } \\
\text { Falsedad } \\
\text { Privilegio } \\
\text { Abuso de poder }\end{array}$ \\
\hline $\begin{array}{l}\text { Fuerzas Armas } \\
\text { y Seguridad }\end{array}$ & $\begin{array}{l}\text { Figura actor que representa al } \\
\text { colectivo ligado a la dictadura } \\
\text { militar que se ha beneficiado pro- } \\
\text { ducto de los acuerdos políticos. }\end{array}$ & $\begin{array}{l}\text { Corrupción } \\
\text { Privilegios } \\
\text { Abuso de poder } \\
\text { Crueldad }\end{array}$ \\
\hline Genocidas & $\begin{array}{l}\text { Miembros de las Fuerzas Ar- } \\
\text { madas y Seguridad que están } \\
\text { en libertad y/o que han sido } \\
\text { procesados por los tribunales } \\
\text { nacionales. }\end{array}$ & $\begin{array}{l}\text { Criminales } \\
\text { Culpables } \\
\text { Injusticia } \\
\text { Dictadura } \\
\text { Violencia } \\
\text { Crueldad }\end{array}$ \\
\hline $\begin{array}{l}21^{\mathrm{a}} \text { Marcha de } \\
\text { Resistencia }\end{array}$ & $\begin{array}{l}\text { Movilización popular realizada } \\
\text { en diciembre de 2001. En dicha } \\
\text { instancia las Madres de la Plaza } \\
\text { de Mayo convocaron al pueblo } \\
\text { argentino para luchar contra el } \\
\text { "Terrorismo de Estado". }\end{array}$ & $\begin{array}{l}\text { Resistencia } \\
\text { Acción colectiva } \\
\text { Justicia } \\
\text { Cohesión social } \\
\text { Defensa de la Nación }\end{array}$ \\
\hline
\end{tabular}




\begin{tabular}{|c|c|c|}
\hline $\begin{array}{l}\text { Nación } \\
\text { Argentina }\end{array}$ & $\begin{array}{l}\text { Figura actor que representa al } \\
\text { pueblo argentino y que deman- } \\
\text { da-por medio de la Asociación } \\
\text { de las Madres de la Plaza de } \\
\text { Mayo- el cumplimiento de } \\
\text { los compromisos contraídos } \\
\text { por el Estado producto de la } \\
\text { situación política y económi- } \\
\text { ca del país. }\end{array}$ & $\begin{array}{l}\text { Compromiso } \\
\text { Respeto } \\
\text { Dignidad } \\
\text { Cohesión } \\
\text { Sacrificio } \\
\text { Justicia } \\
\text { Solidaridad } \\
\text { Víctima }\end{array}$ \\
\hline $\begin{array}{l}\text { Campaña } \\
\text { Internacional } \\
\text { El mundo } \\
\text { entero }\end{array}$ & $\begin{array}{l}\text { Figura actor/lugar que repre- } \\
\text { senta la acción que pretende } \\
\text { ejecutar la Asociación de las } \\
\text { Madres de la Plaza de Mayo } \\
\text { con el objetivo de informar al } \\
\text { mundo lo que ocurre en el país } \\
\text { y, a su vez, gestionar el apoyo } \\
\text { a sus demandas. }\end{array}$ & $\begin{array}{l}\text { Reconocimiento } \\
\quad \text { internacional } \\
\text { Acción colectiva } \\
\text { Organización } \\
\text { Presión política } \\
\text { Apoyo / Respaldo } \\
\text { Cooperación } \\
\text { Denuncia }\end{array}$ \\
\hline $\begin{array}{l}\text { Sistema } \\
\text { Político }\end{array}$ & $\begin{array}{l}\text { Figura actor que representa la } \\
\text { corrupción y es identificado } \\
\text { como el causante de la crisis } \\
\text { social, política y económica } \\
\text { que afecta a la Nación. }\end{array}$ & $\begin{array}{l}\text { Corrupción } \\
\text { Injusticia } \\
\text { Inestabilidad } \\
\text { Crisis } \\
\text { Conflicto } \\
\text { Caos }\end{array}$ \\
\hline $\begin{array}{l}\text { Presidente } \\
\text { Gobernadores } \\
\text { Diputados } \\
\text { Senadores } \\
\text { Concejales } \\
\text { Jueces } \\
\text { Políticos } \\
\text { Ladrones } \\
\text { Burocracia } \\
\text { Sindical }\end{array}$ & $\begin{array}{l}\text { Conjunto de actores represen- } \\
\text { tantes del Estado y del sistema } \\
\text { político corrupto, represor, in- } \\
\text { justo y terrorista. Todos son } \\
\text { responsables de las reiteradas } \\
\text { injusticias, del hambre y la de- } \\
\text { solación del pueblo argentino. }\end{array}$ & $\begin{array}{l}\text { Corrupción } \\
\text { Culpables } \\
\text { Abuso de poder } \\
\text { Injusticia } \\
\text { Decadencia } \\
\text { Servidumbre } \\
\text { Egoísmo } \\
\text { Responsabilidad }\end{array}$ \\
\hline $\begin{array}{l}\text { EEUU } \\
\text { Multinacionales } \\
\text { Fondo } \\
\text { Monetario } \\
\text { Internacional }\end{array}$ & $\begin{array}{l}\text { Agentes promotores del te- } \\
\text { rrorismo de Estado. Figura } \\
\text { actor identificado con el im- } \\
\text { perialismo radical a través del } \\
\text { uso de la violencia, la presión } \\
\text { económica y el control de las } \\
\text { acciones de la élite política } \\
\text { argentina. }\end{array}$ & $\begin{array}{l}\text { Poder } \\
\text { Control } \\
\text { Imperialismo } \\
\text { Corrupción } \\
\text { Violencia } \\
\text { Terrorismo } \\
\text { Enfermedad }\end{array}$ \\
\hline
\end{tabular}




\begin{tabular}{|c|c|c|}
\hline $\begin{array}{l}\text { Chiche } \\
\text { Duhalde }\end{array}$ & $\begin{array}{l}\text { Mujer del Presidente Eduardo } \\
\text { Duhalde, quien es identificada } \\
\text { como un operador político que } \\
\text { utiliza los recursos financieros } \\
\text { obtenidos de la Iglesia y de Eu- } \\
\text { ropa para redistribuir los dine- } \\
\text { ros entre los gobernadores del } \\
\text { país que apoyan al Presidente } \\
\text { Duhalde. }\end{array}$ & $\begin{array}{l}\text { Corrupción } \\
\text { Injusticia } \\
\text { Representación del } \\
\text { Estado } \\
\text { Abuso de poder }\end{array}$ \\
\hline $\begin{array}{l}\text { Piqueteros } \\
\text { Hijos } \\
\text { Niños } \\
\text { A s a m b l e a s } \\
\text { Barriales } \\
\text { Revoluciona- } \\
\text { rios } \\
\text { Pueblo } \\
\text { Luchadores Po- } \\
\text { pulares }\end{array}$ & $\begin{array}{l}\text { Figuras utilizadas dentro del } \\
\text { discurso como representación } \\
\text { del sufrimiento, dolor y deses- } \\
\text { peración causada por la acción } \\
\text { de los gobiernos corruptos, de } \\
\text { un Estado represor y por la cri- } \\
\text { sis económica. A su vez, son el } \\
\text { referente directo de la defensa } \\
\text { del pueblo y sus acciones son } \\
\text { justificadas en virtud de un te- } \\
\text { rrorismo de Estado que golpea } \\
\text { permanentemente al pueblo } \\
\text { argentino y latinoamericano. }\end{array}$ & $\begin{array}{l}\text { Defensa } \\
\text { Víctima } \\
\text { Resistencia } \\
\text { Lucha } \\
\text { Sacrificio } \\
\text { Esperanza } \\
\text { Unión /Cohesión } \\
\text { Identidad } \\
\text { Sufrimiento } \\
\text { Libertad }\end{array}$ \\
\hline
\end{tabular}




\section{Bibliografía}

Auyero, J. (2004), “¿Por qué grita esta gente? Los medios y los significados de la protesta popular en la Argentina de hoy”, en América Latina Hoy, Abril, $N^{\circ}$ 036, Universidad de Salamanca, pp. 161-185.

Bensaïd, D. (2006), Clases, plebes, multitudes, Palinodia, Santiago de Chile.

Blumer, H. (1946), “Collective behavior”, en Lee, A. (ed). New outline of the principles of sociology, Barnes and Noble, New York, pp.162-222.

Borón, A. (2006a). “Después del saqueo: el capitalismo latinoamericano a comienzos del nuevo siglo”, en Borón, A y Lechini, G. (2006), Política y movimientos sociales en un mundo hegemónico. Lecciones desde África, Asia y América Latina, CLACSO, Buenos Aires.

Idem (2006b), “Crisis de la democracia y movimientos sociales en América Latina: Notas para una discusión”, en Revista Observatorio Social de América Latina, Año VII, No 20, pp. 289-304.

Calderón, F y Jelin, E. (1987), “Clases sociales y movimientos sociales en América Latina”, en Proposiciones, 14, SUR, Santiago de Chile.

Costa, R y Mozejko, D. (2001), El discurso como práctica. Lugares desde donde se escribe la historia, Homo Sapiens Ediciones, Rosario.

Courtés, J. (1995), Análisis semiótico del discurso. Del enunciado a la enunciación, Gredos, Madrid.

D’Alessandro, M. (1998), “Los movimientos sociales en la transición democrática. El caso de las Madres de la Plaza de Mayo: Sentimiento y discurso”, en Revista América Latina Hoy, N²0, pp. 41-45.

Del Valle Rojas, C. (2006), Comunicación participativa, Estado-nación y democracia. Discurso, tecnología y poder, Ediciones Universidad de la Frontera, Temuco.

Eckstein, S. (2001), “¿Qué ha sido de todos los movimientos? Los movimientos sociales latinoamericanos en vísperas del nuevo milenio”, en Eckstein, S. (Coord), Poder y protesta popular. Movimientos sociales latinoamericanos, Siglo Veintiuno Editores, México.

Galante, M, Luque, B y Fuks, M. (2006), “Sobre Terrorismo de Estado y resistencia: Los orígenes de Madres de la Plaza de Mayo”, en Areces, N y Bonaudo, M, Movimientos sociales. Experiencias históricas. Tendencias y conflictos, Anuario $\mathrm{N}^{\circ} 21$, Escuela de Historia, Universidad Nacional de Rosario, Homo Sapiens Ediciones, Rosario.

Gandásegui, M. (1989), “Panamá: Unidad nacional y unidad popular. Al- 
ternativas para los movimientos sociales”, en Camacho, D y Menjívar, R. (2005), Los movimientos populares en América Latina, Siglo Veintiuno Editores, México.

García, D y Palermo, V. (1983), "El movimiento de los Derechos Humanos en la transición a la democracia en Argentina”, en Camacho, D y Menjívar, R. (2005), Los movimientos populares en América Latina, Siglo Veintiuno Editores, México.

Garretón, M. A. (2006), “Sociedad civil y ciudadanía en la problemática latinoamericana actual”, en Cheresky, Isidoro (ed), Ciudadanía, sociedad civil y participación política, Miño y Dávila Editores, Buenos Aires.

Idem (2000), La sociedad en que vivi(re)mos. Introducción sociológica al cambio de siglo, LOM, Santiago de Chile.

Idem (2002), “La transformación de la acción colectiva en América Latina”, en Revista de la Cepal, N76, pp.7-24.

Giroud, J y Panier, L. (1988), Semiótica, Verbo Divino Ediciones, Navarra.

Goicovic, I. (1996), "Movimientos sociales en la encrucijada. Entre la integración y la ruptura”, en Revista Última Década, № 5.

Halperín Donghi, T, Glade, W, Thorp, R, et al. (2002), Historia económica de América Latina desde la independencia hasta nuestros días, Crítica, Barcelona.

Iazzetta, O. (2007), Democracia en busca de Estado. Ensayos sobre América Latina, Homo Sapiens Ediciones, Rosario.

Jäger, S. (2001), “Discurso y conocimiento: Aspectos teóricos y metodológicos de la crítica del discurso y del análisis de dispositivos”, en Wodak, R y Meyer, M (ed.) (2003), Métodos de análisis crítico del discurso, Gedisa, Barcelona.

Mayorga, A, Del Valle, C y Nitrihual, L. (2009), “Movimientos sociales en América Latina. Reflexiones en torno a la (des)obediencia de una tradición (des)bordada por la gubernamentalidad”, en Revista Encrucijadas. Diálogos y Perspectivas, Número 3, Febrero, Centro de Investigaciones Postdoctorales (CIPOST) de la Facultad de Ciencias Económicas y Sociales, Universidad Central de Venezuela (UCV), pp. 167-184.

McAdam, D. (1982), Political process and the development of Black insurgency 1930-1970, 2ed, The University of Chicago Press, Chicago.

Melucci, A. (1996), Challenging codes: collective action in the information age, Cambridge University Press, Cambridge. 
Meyer, D y Staggenborg, S. (1996), “Movements, Countermovements, and the Structure of Political Opportunity", in The American Journal of Sociology, Vol 101, N6, pp. 1628-1660.

Negri, A. y Cocco, G. (2006), Global. Biopoder y luchas en una América Latina globalizada, Paidós, Buenos Aires.

Noé, A. (1989), “Los movimientos sociales en Brasil 1970-1982”, en Camacho, D y Menjívar, R. (2005), Los movimientos populares en América Latina, Siglo Veintiuno Editores, México.

O‘Donnell, G. (1993), “Estado, democratización y ciudadanía”, en Revista Nueva Socieda, N 128 , pp. 62-87.

Idem (2004), “Acerca del Estado en América Latina contemporánea. Diez tesis para discusión”, en Informe PNUD: La democracia en América Latina. Hacia una democracia de ciudadanas y ciudadanos. Contribuciones para el debate, Alfaguara, Buenos Aires.

Offe, C. (1992), Partidos políticos y nuevos movimientos sociales, Sistema, Madrid.

Potter, J. (1998), La representación de la realidad. Discurso, retórica y construcción social, Paidós, Barcelona.

Quijano, A. (1993), “Colonialidad del poder, eurocentrismo y América Latina”, en Lander, E (comp), La colonialidad del saber: eurocentrismo y ciencias sociales. Perspectivas latinoamericanas, CLACSO, Buenos Aires.

Rossi, F. (2006), “Movimientos sociales”, en Aznar, L y De Luca, M (coord.), Política. Cuestiones y problemas, Emecé, Buenos Aires.

Santos, B y Avritzer, L. (2004), “Introducción. Para ampliar el canon democrático”, en Santos, B (Coord), Democratizar la democracia. Los cambios de la democracia participativa, Fondo de Cultura Económica, México.

Smelser, N. (1989), Teoría del comportamiento colectivo, Fondo de Cultura Económica, México.

Svampa, M. (2005), La sociedad excluyente, Taurus, Buenos Aires.

Tarrow, S. (1998), Power in movement. Social movement and contentious politics, 2ed, Cambridge University Press, Cambridge.

Idem (2005), The new transnational activismo, 2ed, Cambridge University Press, Cambridge. 
Tilly, Ch. (2004), Contention and democracy in Europe 1650-2000, Cambridge University Press, Cambridge.

Idem (2005), “Los movimientos sociales entran en el siglo XXI”, (Trad. Marta Latorre), en Política y Sociedad, Vol.42, N², pp.11-35.

Touraine, A. (1995), ¿Qué es la democracia?, Fondo de Cultura Económica, México.

Idem (2000), Crítica de la Modernidad, Fondo de Cultura Económica, México. 